\title{
Luz, câmera, alfabetização científica! Possibilidades epistemológicas no antagonismo ciência-pseudociência da série Cosmos de Carl Sagan
}

Light, Camera, Scientific Literacy! Epistemological possibilities in the science-pseudoscience antagonism of the Cosmos series by Carl Sagan

Marcos Gervânio de Azevedo Melo ${ }^{1}$

\section{Resumo}

O objetivo desse artigo é investigar contribuições ao processo de alfabetização científica e tecnológica quando se busca compreender a distinção entre ciência e pseudociência pela análise da série Cosmos de Carl Sagan. No terceiro capítulo desta série, fala-se da ligação que existira entre astronomia e astrologia, oportunizando-se interpretações nas quais os planetas, por exemplo, afetariam o caráter e o destino das pessoas. Este capítulo possibilita refletir sobre visões de ciência, oportunizando-se contemplar as concepções indutivista, o raciocínio lógico dedutivo, bem como o falsificacionismo de Popper. Contudo, oportunizase, também, pensar sobre as características da pseudociência e o quanto estivera ligada à ciência noutrora. Foi possível articular trechos da série a um dos eixos estruturantes de alfabetização científica propostos por Sasseron e Carvalho e, por meio da análise de conteúdo de Bardin, estabelecer inferências. A simples possibilidade de se compreender que a ciência elimina seus erros para prosperar e que suas hipóteses surgem oferecendo a possibilidade de serem refutadas, representa um elemento fundamental para diferenciá-la da pseudociência, pois a hipótese pseudocientífica, por outro lado, é gerada buscando alcançar invulnerabilidade a qualquer observação que possa refutá-la.

Palavras-chave: Alfabetização científica e tecnológica; ciência e pseudociência; série Cosmos de Carl Sagan.

\section{Abstract}

The aim of this article is to investigate contributions to the process of scientific and technological literacy when it seeks to understand the distinction between science and pseudoscience through the analysis of the Cosmos series by Carl Sagan. In the third chapter of this series, we talk about the link that existed between astronomy and astrology, providing opportunities for interpretations in which the planets, for example, would affect the character and destiny of people. This chapter makes it possible to reflect on views of science, providing opportunities to contemplate inductivist conceptions, deductive logical reasoning, as well as Popper's falsificationism. However, it is also an opportunity to think about the characteristics of pseudoscience and how much it had been linked to science in the past. It was possible to articulate excerpts from the series to one of the structuring axes of scientific

\footnotetext{
${ }^{1}$ Universidade Federal do Oeste do Pará - UFOPA | marcosgervanio@gmail.com
} 
literacy proposed by Sasseron and Carvalho and, through Bardin's content analysis, establish inferences. The simple possibility of understanding that science eliminates its mistakes to prosper and that its hypotheses arise offering the possibility of being refuted, represents a fundamental element to differentiate it from pseudoscience, since the pseudoscientific hypothesis, on the other hand, is generated seeking to achieve invulnerability to any observation that might refute it.

Keywords: Scientific and technological literacy; science and pseudoscience; Cosmos series by Carl Sagan.

\section{Introdução}

Quando Paulo Freire aplica seu método de alfabetização, no início da década de 1960, entremostra que tinha como intenção um processo que oportunizasse leitura de mundo e que servisse de instrumento de conscientização para as camadas populares. Essa proposta dialógica, libertadora e problematizadora, obviamente, não agradou as camadas mais conservadoras da elite brasileira e, por isso, o educador brasileiro foi preso em 1964 e, posteriormente, exilado para o Chile (FREIRE, 1980). Isso nos faz questionar a real liberdade que se tem para efetivamente alfabetizar em países da América Latina como o Brasil.

Na Educação Científica, por exemplo, recomenda-se que o professor ou professora esteja "preparado para aprofundar os conhecimentos e adquirir outros novos" (GIL-PÉREZ; CARVALHO, 2009, p. 22), mas a tentativa de aprofundar uma das temáticas transversais, proposta por documentos que norteiam a educação (BRASIL, 1997, 2000, 2002, 2006) qual seja a Orientação Sexual cuja intenção era a de evitar gravidez precoce e doenças transmitidas pelo ato sexual, fez com que algumas escolas de natureza evangélica deixassem de adotar quatro dos livros de um autor que produz materiais de Ciências Naturais voltados ao ensino fundamental (LAGO, 2017).

Não é difícil apresentar outros exemplos de fatos que objetivam, claramente, silenciar e, inclusive, alienar a sociedade, privando-a de conhecimento, pois a educação é, sobretudo, um ato político e as decisões que a conduzem não são, assim, tão democráticas quanto gostaríamos. Ao falar sobre alfabetização científica, por exemplo, Chassot (2011) menciona que "custa crer que a educação que é oferecida busque fazer com que aqueles e aquelas que a recebem se tornem mais críticos" (p. 109).

Assim, nesse contexto de tateamento de uma cultura do silêncio, é preciso pensar que a vulnerabilidade cognitiva de um indivíduo pode representar uma possibilidade imensa de enriquecimento para outrem e parece não haver dúvidas de que o analfabetismo científico contribui, sobremaneira, para isso, pois em tempos de pós-verdade, em que se mitiga e se demoniza o entendimento da ciência, são as crenças pessoais e emoções que influenciam a opinião pública e não os fatos objetivos (CUNHA; CHANG, 2021), ou seja, passamos a acreditar em "explicações do mundo simplesmente porque queremos acreditar, desconsiderando ou ignorando critérios e indicadores que nos apontem para a inadequação daquela explicação" (PILATI, 2018, p. 42).

Apesar do acesso à internet ter proporcionado contribuições incomensuráveis para se promover a alfabetização científica da sociedade, possibilita também o aumento de posturas negacionistas e anticientíficas que compreendem, por exemplo, os movimentos terraplanista e antivacina. Além disso, internet e redes sociais amplificam igualmente 0 acesso a outros tipos de manifestações infestadas de credulidades como a pseudociência. 
Sobre isso, num estudo realizado em 2019 com 22 licenciandos em ensino de ciências, que estavam em fase de conclusão de curso numa universidade do interior do Paraná, foi possível perceber que 19, desses futuros professores de ciências, não conseguiam diferenciar conhecimento científico de manifestações pseudocientíficas (MELO, 2019, 2020). É preciso lembrar que um objetivo importante da alfabetização científica e tecnológica ACT é possibilitar que as pessoas adquiram conhecimento científico suficiente para que possam exercitar a cidadania (AIKENHEAD, 1994; CACHAPUZ; 2011; CHASSOT, 2011; SASSERON; CARVALHO, 2011).

Por isso, colocar luz sobre tais movimentos e manifestações, procurando entender suas características, objetivos e natureza, "parece ser uma necessidade no ensino de ciências, principalmente sob ponto de vista epistemológico, esclarecendo seus critérios simplificadores e limitantes" (MARINELI, 2020, p. 1189). Assim, oportunizando-se um processo de alfabetização científica cívica, o indivíduo estará se preparando para tomar decisões referentes à ciência e suas articulações com a sociedade; enquanto um processo de alfabetização científica cultural proporcionará refletir questões epistemológicas envolvendo aspectos relativos à Natureza da Ciência (NdC) (SHEN, 1975).

Alguns objetos de aprendizagem podem contribuir para essa reflexão epistemológica no ensino de ciências, possibilitando discutir distinções entre ciência e pseudociência, destacando-se as obras cinematográficas como filmes e documentários.

Diante disso, a questão que norteia esse estudo é alicerçada na seguinte indagação: quais contribuições ao processo de ACT podem surgir na Educação Científica quando se busca compreender a distinção entre ciência e pseudociência pela análise da série Cosmos de Carl Sagan?

Tal questão se mostra importante quando se compreende que a ciência inicia uma intensa sensação de prodígio, porém a pseudociência também e, por isso, sempre haverá lugar para a pseudociência quando não compreendemos perfeitamente a necessidade de provas pertinentes para que uma afirmação de conhecimento seja aceita (SAGAN, 1996).

Assim, o objetivo desse artigo é investigar contribuições ao processo de ACT quando se busca compreender a distinção entre ciência e pseudociência pela análise da série Cosmos de Carl Sagan.

\section{A série Cosmos de Carl Sagan}

Criada no final década de 1970 pelo cientista norte-americano Carl Sagan (1934-1996) e pela esposa, a produtora de projetos de divulgação da ciência, Ann Druyan, a série Cosmos surge como proposta para estimular o interesse pela ciência, sendo veiculada inicialmente em 1980 no canal PBS de televisão estadunidense (MARTINAZZO; MARTINS, SILVA, 2018).

Nesse documentário, o astrofísico Carl Sagan procura nos proporcionar uma explicação do Universo desde sua origem até os dias de hoje e apresenta uma sequência de aspectos históricos que possibilitam compreender como a ciência nasce e se desenvolve, os erros que caracterizam o empreendimento da ciência e os interesses que podem conduzir sua construção.

Assim, com o objetivo de oportunizar conhecimento científico às pessoas, Sagan metaforicamente viaja com sua "nave da imaginação" fazendo uma verdadeira jornada pelo Espaço Sideral, destaca o período da história antiga mostrando personagens importantes para a ciência como Eratóstenes (276 AEC - 194 AEC) que descobre que a Terra não é 
plana, mas apresenta uma curvatura que a caracteriza como esférica, e avança cronologicamente, capítulo por capítulo, com a divulgação do conhecimento científico.

No terceiro capítulo ${ }^{2}$ da série, o astrônomo e cosmólogo americano nos remete aos tempos de Cláudio Ptolomeu (90-168), Nicolau Copérnico (1473-1543), Tycho Brahe (15461601) e Johannes Kepler (1571-1630) que atribui a ideia de força como a causadora do movimento dos planetas em suas respectivas órbitas. Kepler é lembrado como aquele que daria os primeiros passos rumo à revolução científica moderna, mas também como um praticante da astrologia em complemento à astronomia. Nesse capítulo, apresentam-se objetos de estudo dos astrônomos, destacando-se as Plêiades, os cemitérios estelares como a Nebulosa do Caranguejo, os planetas como Marte, Júpiter e Saturno. Contudo, fala-se também da ligação que existira entre astronomia e astrologia, oportunizando-se interpretações nas quais os planetas, por exemplo, afetariam o caráter e o destino das pessoas.

No último capítulo ${ }^{3}$, Sagan nos apresenta uma sucessão de questões sobre ciência e tecnologia - C\&T nos fazendo compreender que apesar da ciência não ser perfeita, ela é a melhor opção que possuímos, pois foi com os seus métodos e produtos que conseguimos explorar o Cosmos. Contudo, o divulgador científico ressalta sobre a necessidade de aprendermos a utilizar C\&T com responsabilidade, pois a mesma tecnologia serve tanto para o bem quanto para o mal. Sagan nos alerta sobre os perigos das armas nucleares ao descrever a Terra como um organismo único que parece estar em guerra consigo mesmo. Além disso, destaca que precisamos distinguir nossos preconceitos das verdades, mas lembra que não há lugar para verdades sagradas na ciência.

\section{A dimensão epistemológica no ensino de ciências}

Ao se observar o título do livro de Chalmers (1993), - o que é ciência, afinal? -_talvez não seja possível inferir inicialmente que a leitura desta obra pode contribuir também para se compreender o que não é ciência. Claro, a obra oferece possibilidades de uma compreensão sobre visões de ciência, destacando-se: a indutivista, o raciocínio lógico dedutivo, o falsificacionismo de Popper, os programas científicos de Lakatos, as revoluções científicas de Kuhn e o anarquismo científico de Feyerabend. Contudo, o livro não esgota as concepções de ciência, pois poder-se-ia continuar tal compreensão buscando-se referências em Gaston Bachelard, Bruno Latour, Larry Laudan, entre outros.

Sagan (1996) ressalta que se alguém não entende adequadamente como funciona a ciência, dificilmente terá consciência ao enveredar nas armadilhas da pseudociência.

Assim, as diversas visões de ciência proporcionam contactar diferentes critérios universais para demarcação entre ciência e pseudociência e, inclusive, possibilitam atribuir críticas a tais critérios como o faz Thomas Kuhn ao diferenciar ciência e pseudociência pela existência de um paradigma e não por um critério universal (CHALMERS, 1993). Independentemente do caminho a ser traçado, não há dúvidas de que o contato com a dimensão epistemológica da ciência, possibilitando valorizar o ensino sobre a ciência, contribui para a ACT dos atores e auxilia no desenvolvimento de uma consciência mais crítica sobre o mundo (SASSERON; CARVALHO, 2011). IsSO, claro, é motivo de resistência no

\footnotetext{
2 Disponível em: https://youtu.be/kgsz7AGNlyU. Acesso em: 20 de dez. 2020.

3 Disponível em: https://youtu.be/ljNWnT9tuno. Acesso em: 20 de dez. 2020.
} 
momento de seleção de um conteúdo, pois "o saber escolar é também, e sobretudo, um saber político." (CHASSOT, 2011, p. 214).

Por isso, inserir a dimensão epistemológica da ciência no ensino de ciências representa um caminho para "a reflexão sobre a produção da ciência, sobre seus fundamentos e métodos, sobre seu crescimento, sobre os contextos de descoberta" (CACHAPUZ et al., 2011, p. 70). Porém o conteúdo epistemológico contribui igualmente como um instrumento de conscientização e de leitura de mundo, possibilitando compreender também que a má compreensão da ciência representa um convite a adoção de pseudociências (PILATI, 2018), pois estas parecem empregar dos mesmos métodos e descobertas basilares da ciência, mas na realidade são completamente infiéis à sua natureza (SAGAN, 1996;).

\section{Procedimentos metodológicos}

O estudo inicia com a contemplação dos 13 episódios da obra cinematográfica Cosmos de Carl Sagan cuja intenção era a de escolher cenas que pudessem oportunizar uma comparação entre ciência e pseudociência. Tal série foi utilizada em função de sua importância para a divulgação científica e, também, por ser uma obra do autor do livro: o mundo assombrado pelos demônios: a ciência vista como uma vela no escuro, que busca refletir, entre outras coisas, o espaço ocupado pela pseudociência nos meios de comunicação. Após a apreciação dos episódios, decidiu-se utilizar o terceiro capítulo da série, intitulado A harmonia dos mundos, pois entremostra uma coexistência de atividades científicas e pseudocientíficas nas ações de Johannes Kepler (1571-1630).

Diante disso, alguns trechos desse episódio passaram a formar a unidade de contexto, buscando-se realizar a análise de conteúdo de Bardin (2011). Como tal autora recomenda aspectos temáticos nas unidades de registro, diante de objetos de comunicação, dois temas foram abordados nesta unidade: observação como fonte de conhecimento e ciência e pseudociência. Tais temáticas se entrelaçam, de certa forma, às respectivas subcategorias: visões indutivista e dedutivista da ciência e visão falsificacionista da ciência.

As subcategorias estão articuladas a um dos eixos estruturantes de alfabetização cientifica proposto por Sasseron e Carvalho (2011), indicado a priori como categoria nesse estudo, qual seja, a compreensão da natureza das ciências e dos fatores éticos e políticos que circundam sua prática.

Finalmente, a análise de conteúdo alcançou a etapa de inferência para a compreensão do objeto de estudo, buscando-se suporte no referencial teórico para uma interpretação dos trechos destacados na unidade de contexto.

Esse processo é apresentado no quadro 1, que é acompanhado por mapas conceituais, buscando-se ampliar a possibilidade de visualização e compreensão de características tanto da ciência como da pseudociência.

\section{Análise do documentário Cosmos}

Nesta seção, mostra-se a análise do documentário Cosmos por meio da metodologia da Análise de Conteúdo de Bardin (2011), possibilitando-se entrever contribuições da mencionada obra cinematográfica à promoção da ACT.

O quadro 1 esboça o processo de análise do documentário. 
Quadro 1: Análise de conteúdo de trechos do documentário Cosmos

\begin{tabular}{|c|c|c|c|}
\hline Categoria & Subcategoria & $\begin{array}{l}\text { Unidade de } \\
\text { Registro }\end{array}$ & Unidades de contexto \\
\hline \multirow[b]{2}{*}{$\begin{array}{c}\text { Compreensão da } \\
\text { natureza das } \\
\text { ciências e dos } \\
\text { fatores éticos e } \\
\text { políticos que } \\
\text { circundam sua } \\
\text { prática. }\end{array}$} & $\begin{array}{c}\text { Visões } \\
\text { Indutivista e } \\
\text { Dedutivista da } \\
\text { ciência }\end{array}$ & $\begin{array}{c}\text { Observação } \\
\text { como fonte de } \\
\text { conhecimento }\end{array}$ & $\begin{array}{l}\text { Em um trecho, Carl Sagan diz que para defender } \\
\text { seu modelo de sólidos alinhados, Kepler decidiu } \\
\text { que as observações planetárias, até então aceitas, } \\
\text { estariam imprecisas. Sagan lembra que "Tycho } \\
\text { possui as melhores observações, também tem } \\
\text { colaboradores, só Ihe falta o arquiteto que daria } \\
\text { utilidade a isso tudo. Tycho foi incapaz de } \\
\text { transformar as suas observações em uma teoria do } \\
\text { sistema solar coerente!". Sagan se refere as } \\
\text { "observações do aparente movimento de Marte } \\
\text { através das constelações obtidas em um período } \\
\text { de muitos anos". }\end{array}$ \\
\hline & $\begin{array}{c}\text { Visão } \\
\text { Falsificacionista } \\
\text { da ciência }\end{array}$ & $\begin{array}{c}\text { Ciência e } \\
\text { Pseudociência }\end{array}$ & $\begin{array}{l}\text { Sagan apresenta as leis de Kepler: A Lei das } \\
\text { Órbitas, a Lei das Areas e a Lei dos Períodos. } \\
\text { Antes, porém, Sagan discorre sobre o movimento } \\
\text { dos planetas, em especial, o movimento em forma } \\
\text { de laços de Marte, e pergunta: "como explicar o } \\
\text { movimento giratório dos planetas no céu, (Marte, } \\
\text { por exemplo)?". Posteriormente apresenta os } \\
\text { modelos de Ptolomeu e Copérnico e diz: "A } \\
\text { confrontação entre as duas visões do cosmos } \\
\text { (ptolomaica e copernicana), centrada na Terra e } \\
\text { centrada no Sol, atingiu seu clímax com um } \\
\text { homem [Kepler] que como Ptolomeu, era tanto } \\
\text { astrônomo quanto astrólogo. Sagam falou ainda } \\
\text { que "apoiado pela igreja, na idade das trevas, o } \\
\text { modelo de Ptolomeu evitou efetivamente o avanço } \\
\text { da Astronomia por } 1500 \text { anos" e ressaltou que o } \\
\text { modelo copernicano "irritou muita gente; a igreja } \\
\text { católica, mais tarde, pois o trabalho de Copérnico } \\
\text { em sua lista de livros proibidos e Martinho Lutero } \\
\text { descreveu Copérnico com estas palavras: '[...] as } \\
\text { pessoas dão ouvido a um astrólogo presunçoso, } \\
\text { esse tolo quer reverter toda a ciência da } \\
\text { astronomia'". Finalmente Sagan destaca que: } \\
\text { "Ptolomeu tinha dito que o movimento dos } \\
\text { planetas através das estrelas dos zodíacos eram } \\
\text { presságios dos fatos aqui embaixo" e pergunta: } \\
\text { "Foi à influência de Marte e Vênus que fez de seu } \\
\text { pai um homem brutal? Um mercenário que o } \\
\text { abandonou? Será que uma conjunção infeliz de } \\
\text { planetas e um signo adverso fez de sua mãe uma } \\
\text { mulher perversa e briguenta? Durante uma aula de } \\
\text { astrologia, Kepler inscreveu dentro do círculo dos } \\
\text { zodíacos um triângulo com três lados iguais; ele } \\
\text { então notou, quase que por acaso, que um círculo } \\
\text { menor, inscrito dentro do triângulo, tinha a mesma } \\
\text { ligação com o outro círculo do que a órbita de } \\
\text { Júpiter com a órbita de Saturno." }\end{array}$ \\
\hline
\end{tabular}

Fonte: Elaborado pelo autor 
Categoria: Compreensão da natureza das ciências e dos fatores éticos e políticos que circundam sua prática.

Esta categoria se destaca nos trechos do documentário e possibilita refletir sobre as visões indutivista, dedutivista e falsificacionista da ciência, sendo tais elementos os objetos de reflexão que formam as subcategorias.

\section{Subcategoria: Visões indutivista e dedutivista da ciência}

Ao dizer que "Tycho foi incapaz de transformar as suas observações em uma teoria do sistema solar coerente" (COSMOS, 2005, cap. 3), Sagan entremostra o caminho traçado para a construção do conhecimento científico na visão indutivista. Nessa perspectiva, a ciência inicia com a observação que pode ser de experimentos ou de fenômenos (CHALMERS, 1993). Por isso, é preciso perceber que o caminho que levara Kepler às observações de Tycho Brahe, inicia, segundo Sagan, por uma compreensão de Kepler de que as observações dos planetas, realizadas até aquele momento, não estariam precisas, conflitando com seu modelo de sólidos alinhados. Ora, esta lembrança da limitação característica da percepção humana ou das observações realizadas, inclusive com tecnologia, nos remete a uma concepção indutivista ingênua da ciência apontada por Chalmers (1993), que pode ser compreendida, observando-se figura 1.

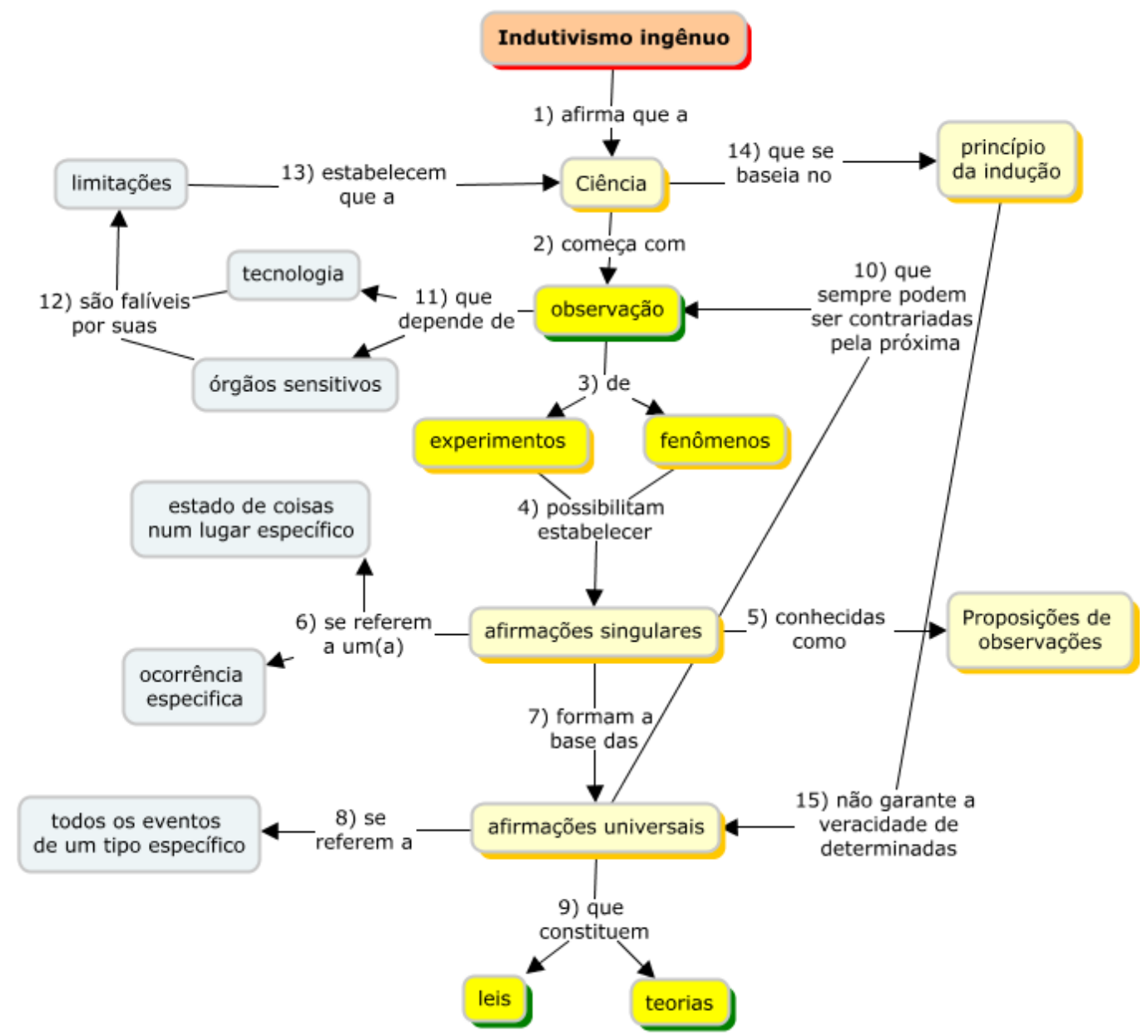

Figura 1 - Visão indutivista ingênua da ciência. Fonte: Elaborado pelo autor 
Percebe-se, observando a figura 1, que leis e teorias que formam o conhecimento científico, como as leis de Kepler, por exemplo, são construídas, nessa visão indutivista, com base em observações. Diante disso, as proposições de observações (afirmações singulares) que formam a base das leis de Kepler nascem de dados colhidos com grande precisão por Tycho Brahe, isto é, "um registro sistemático e preciso das posições dos planetas, especialmente de Marte [que] é o planeta cuja órbita é a de maior excentricidade entre as que Kepler podia estudar" (CANIATO, 2011, p. 66). Percebe-se, assim, o quanto tais observações foram importantes para a formulação das leis de Kepler, pois as teorias que prevaleciam, até então, sobre o movimento dos planetas, estavam relacionadas a explicações que exigiam esferas e circunferências e não elipses, como seriam apresentadas às leis de Kepler.

Assim, as generalizações estabelecidas por Kepler podem ser legitimadas por um indutivista com as seguintes condições apresentadas no quadro 2.

Quadro 2: condições que devem ser satisfeitas para legitimidade das generalizações na visão indutivista da ciência.

\begin{tabular}{|c|c|}
\hline Condições para a generalização & Realizações \\
\hline $\begin{array}{l}\text { 1. O número de proposições de } \\
\text { observação que forma a base } \\
\text { de uma generalização deve ser } \\
\text { grande; }\end{array}$ & $\begin{array}{l}\text { Tycho Brahe constrói mapas celestes, com grande precisão, por } \\
\text { meio de observações planetárias que compreendem: desde } \\
\text { observações do movimento dos planetas até a catalogação de } \\
\text { localização de estrelas, ambas realizadas durante muitos anos. }\end{array}$ \\
\hline $\begin{array}{l}\text { 2. As observações devem ser } \\
\text { repetidas sob uma ampla } \\
\text { variedade de condições; }\end{array}$ & $\begin{array}{l}\text { Brahe utiliza os observatórios de Uraniburgo e Stelleborg, para } \\
\text { observar os movimentos de Marte, mas não se concentra apenas } \\
\text { no planeta vermelho. Realiza sistematicamente observações dos } \\
\text { demais planetas e com instrumentos diferentes em dias } \\
\text { diferentes. }\end{array}$ \\
\hline $\begin{array}{l}\text { 3. Nenhuma proposição de } \\
\text { observação deve conflitar com a } \\
\text { lei universal derivada. }\end{array}$ & $\begin{array}{l}\text { As diversas observações realizadas por Brahe, especialmente as } \\
\text { relativas ao movimento do planeta Marte, proporcionam a Kepler } \\
\text { admitir a elipse como a real formação das órbitas dos planetas e, } \\
\text { com isso, estabelecer suas leis do movimento planetário. }\end{array}$ \\
\hline
\end{tabular}

Fonte: Elaborado pelo autor, com informações de Chalmers (1993); Caniato (2011) e Neves (1986).

Diante das realizações estabelecidas no quadro 2, satisfeitas as condições para legitimar generalizações, pode-se apresentar a formulação das leis de Kepler, descritas por Neves (1986, p. 47) e Cosmos (2005, cap. 3), quais sejam:

- Primeira Lei (Lei das Órbitas): as órbitas dos planetas são elipses, com o Sol ocupando um dos focos destas;

- Segunda Lei (Lei das Áreas): a raio vetor que une planeta-Sol varre áreas iguais em tempos iguais;

- Terceira Lei (Lei dos Períodos): o quadrado do período de revolução do planeta (tempo T que cada um leva para completar uma volta) é proporcional ao cubo de sua distância média do Sol (raio médio da órbita R).

Assim, na perspectiva indutivista, é possível perceber o quanto o crescimento da ciência ocorrerá de forma contínua e acumulativa (GOLDSCHMIDT et al., 2016), pois quanto mais observações acontecerem, mais generalizações podem ser apresentadas.

Por outro lado, percebe-se também que tais afirmações universais não estão livres de serem contrariadas pela próxima observação. Claro, basta comparar as possibilidades observacionais de Tycho Brahe, em meados do século XVI, nos observatórios de Uraniburgo 
e Stelloburg (como ainda não havia sido inventado o telescópio, trabalhava-se a olho nu) (NEVES, 1986), com as possibilidades atuais - cujos observatórios astronómicos utilizam potentes telescópios e, inclusive, espectroscópios para a observação e estudo de estrelas distantes - para constatar que, hoje, mais do que nunca, temos tecnologia que oportuniza melhor alcance e qualidade observacional. Assim, diante da possibilidade de a próxima observação oferecer risco e contrariar a afirmação universal, pode-se perceber que a indução como método científico só poderá garantir as afirmações universais como verdades provisórias.

Além disso, é preciso destacar outra crítica importante referente à indução, pois observações realizadas, como as de Brahe que foram analisadas por Kepler, não estão isentas de serem afetadas pela experiência, conhecimento e expectativa do observador. Há um exemplo bem contemporâneo de Kepler que pode ser apresentado como objeto de reflexão.

O italiano Galileu Galilei (1564-1642) e o inglês Thomas Harriot (1560-1621), utilizando lunetas similares, na mesma época, viram coisas bem diferentes quando observaram a Lua (NEVES et al., 2010). As figuras 2 e 3 mostram os desenhos representativos das Luas de Harriot e Galileu, respectivamente.

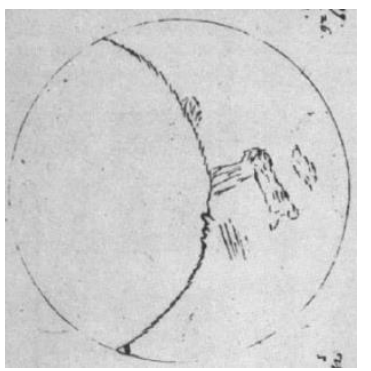

Figura 2 - Primeira llustração da Lua de Harriot. Fonte: Neves e Silva (2010)
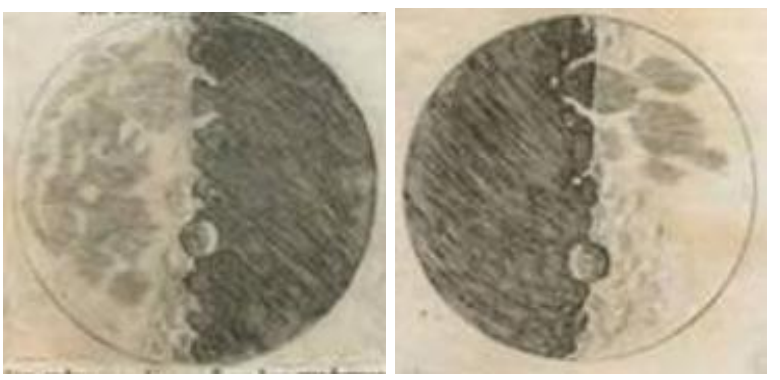

Figura 3 - llustrações da Lua de Galileu. Fonte: Neves e Silva (2010).

Enquanto o desenho de Harriot (figura 2) ilustrava uma Lua apresentando somente manchas desprovidas de significados, as representações imagéticas de Galileu (figura 3) possibilitavam uma noção da superfície lunar repleta de irregularidades que eram reveladas por sombras oriundas de montanhas e crateras, entremostrando, com isso, o quanto Galileu estava habituado à perspectiva e principalmente ao claro-escuro, pois estudara desenho obtendo conhecimento numa formação proporcionada por pintores renascentistas na Itália (BRAGA; GUERRA; REIS, 2004).

Isso revela um interessante problema para a perspectiva indutivista, pois mostra o quanto o conhecimento e a experiência podem afetar diretamente a observação que, por sua vez, representa a origem do conhecimento diante desse método científico. Por isso, pode-se dizer que a mesma imagem do nosso satélite natural se formou sobre as retinas de Galileu e Harriot, mas não podemos concluir que os mencionados astrônomos tiveram experiências perceptivas idênticas. Essa ideia é reforçada pelo desenho da Lua apresentado por Harriot após ter conhecimento das ilustrações de Galileu. A figura 4 esboça a nova representação imagética de Harriot. 


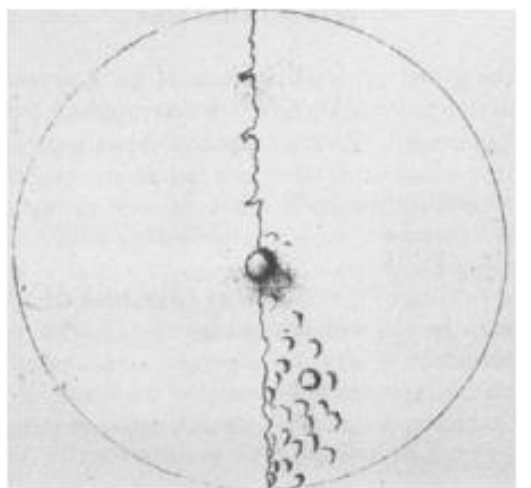

Figura 4 - llustração da Lua de Harriot depois do contato com as observações de Galileu. Fonte:

Neves e Silva (2010)

Percebe-se que após realizar leitura das descrições de Galileu e contemplar seus desenhos, Harriot passa a observar a Lua semelhante à descrição do astrônomo italiano, mas é claro que não possui as técnicas de Galileu (BRAGA; GUERRA; REIS, 2004). Assim como esse acontecimento reforça a ideia de que o conhecimento precede a observação, outras críticas à posição indutivista podem ser reveladas diante dos desenhos de Harriot e Galileu.

A primeira ilustração da Lua apresentada por Harriot, entremostrando apenas uma mancha sem grande significado, revela influências aristotélicas cuja necessidade de os corpos celestes representarem esferas perfeitas parece mostrar que tal ilustração, destacada na figura 2, é fruto de observação guiada pela teoria (NEVES; SILVA, 2010). Assim, a visão indutivista da ciência se depara com um novo problema, pois agora precisa aceitar que as teorias também precedem a observação.

Por outro lado, mesmo diante das críticas apresentadas até aqui, pode-se dizer que o problema da indução não deve ser encarado em termos de uma refutação definitiva, pois a maioria das demais filosofias da ciência apresentam alguma dificuldade similar (CHALMERS, 1993). Nesse contexto, é muito importante contactar o belíssimo trabalho observacional de Tycho Brahe, mas oportunizando refletir o quanto suas observações estariam impregnadas por conhecimento, expectativas e teorias.

Afirmações universais, estabelecidas por indução, como a primeira Lei de Kepler, podem ser utilizadas para realizar previsões e explicações e isso pode ser bem entendido contemplando-se a figura 5.

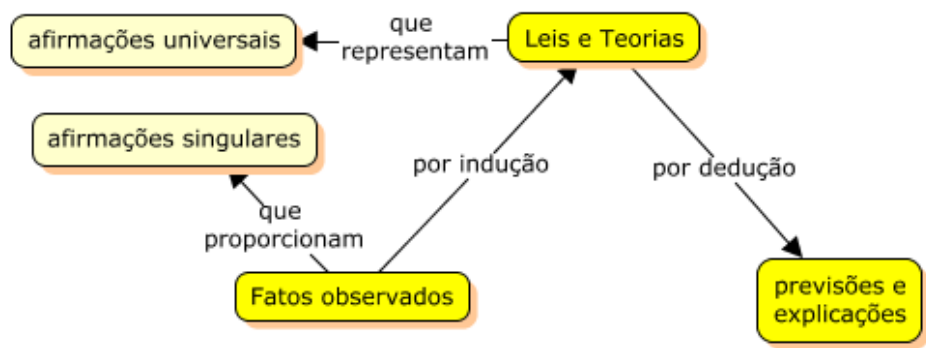

Figura 5 - Utilização de leis e teorias para tecer previsões/explicações. Fonte: Elaborado pelo autor.

Pode-se perceber que afirmações universais, como a primeira Lei de Kepler, estabelecidas de observações, por indução, podem contribuir na realização de previsões e explicações de fenômenos como a descoberta de Netuno, em 1846, cuja interferência na 
órbita esperada do planeta Urano, o fazendo vibrar, fora explicada pela presença de um novo planeta, Netuno.

Esse processo que possibilita prever ou explicar um fenômeno por meio de afirmações universais, estabelecidas por leis e teorias, é conhecido como raciocínio lógico dedutivo (CHALMERS, 1993) e tal concepção de ciência pode ser bem perceptível nas aulas tradicionais de laboratório em que se priorizam verificações singelas da lei, realizando-se demonstrações experimentais para ilustrar uma teoria, pois apresenta-se um fenômeno para se fazer a comprovação de uma teoria que anteriormente tenha sido estudada (AZEVEDO, 2009). Essa visão dedutivista de ciência pode ser compreendida observando-se a figura 6 .

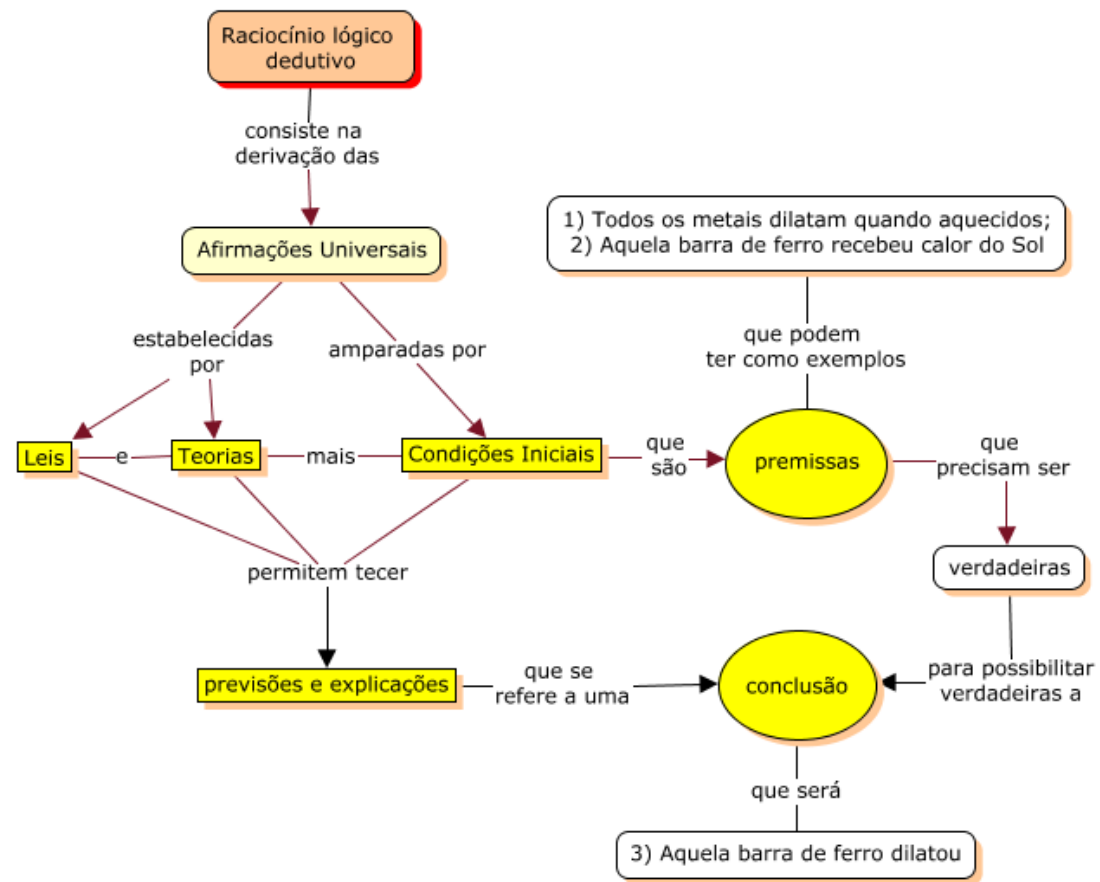

Figura 6 - Raciocínio lógico dedutivo. Fonte: Elaborado pelo autor.

A figura 6 nos permite perceber que, independentemente da experimentação, utilizando-se a lógica, pode-se deduzir certo fenômeno quando se tem afirmações universais. Assim, premissas como a primeira Lei de Kepler, na companhia da Gravitação Universal, amparadas por condições iniciais como a "dança do planeta Urano" num ponto de sua órbita, possibilitam tecer conclusões como a previsão de um novo planeta, Netuno. Porém, quando uma das premissas não for verdadeira (imagine que um observador, agora, invente, como condição inicial, que Plutão tenha "dançado" em sua órbita, mas que tudo não passe de um devaneio em busca de holofotes), teremos que o raciocínio lógico não possibilitará alcançar um resultado (a conclusão será falsa, pois a previsão de um novo planeta, perturbando Plutão, não seria verdadeira).

Assim, retornando aos comentários de Sagan, é preciso lembrar a seguinte fala: "Tycho possui as melhores observações, também tem colaboradores, só lhe falta o arquiteto que daria utilidade a isso tudo" (COSMOS, 2005, cap. 3). Tal "arquiteto" não só formulará leis e teorias, utilizando essas observações, mas poderá fazer previsões derivadas dessas afirmações universais e, diante disso, a base dessas previsões e explicações são, na realidade, as observações. Por isso, considerando-se a fragilidade característica da elaboração das afirmações universais, percebe-se que sempre existirá a possibilidade de 
cometer enganos em relação às deduções, estabelecendo-se a dúvida constante à fidedignidade dos conhecimentos provenientes de propostas dedutivas (GOLDSCHMIDT et al., 2016).

\section{Subcategoria: Visão falsificacionismo da ciência}

Recorrendo-se a perspectivas epistemológicas mais recentes, como o falsificacionismo elaborado por Karl Popper (1902-1994), percebe-se que uma afirmação universal, como a Lei das Órbitas, apresentada por Sagan na série Cosmos, corresponde a uma hipótese que pode ser facilmente falsificável com uma proposição de observação assim enunciada: as órbitas dos planetas são triangulares, com o Sol ocupando o circuncentro formado pelas mediatrizes desse triângulo. Ora, mesmo que nunca seja observada tal proposição, esta representa uma possibilidade de falseamento à primeira Lei de Kepler, pois caso fosse estabelecida como verdadeira, falsificaria a Lei das Órbitas e possibilitaria um crescimento da ciência que, nessa perspectiva falsificacionista, acontece por conjecturas e refutações. Essa possibilidade de falsificar o que conhecemos, o colocando como falho, contribui para mostrar o caráter autocorretivo da ciência (PILATI, 2018).

Essa visão falsificacionista da ciência pode ser compreendida observando-se a figura 7.

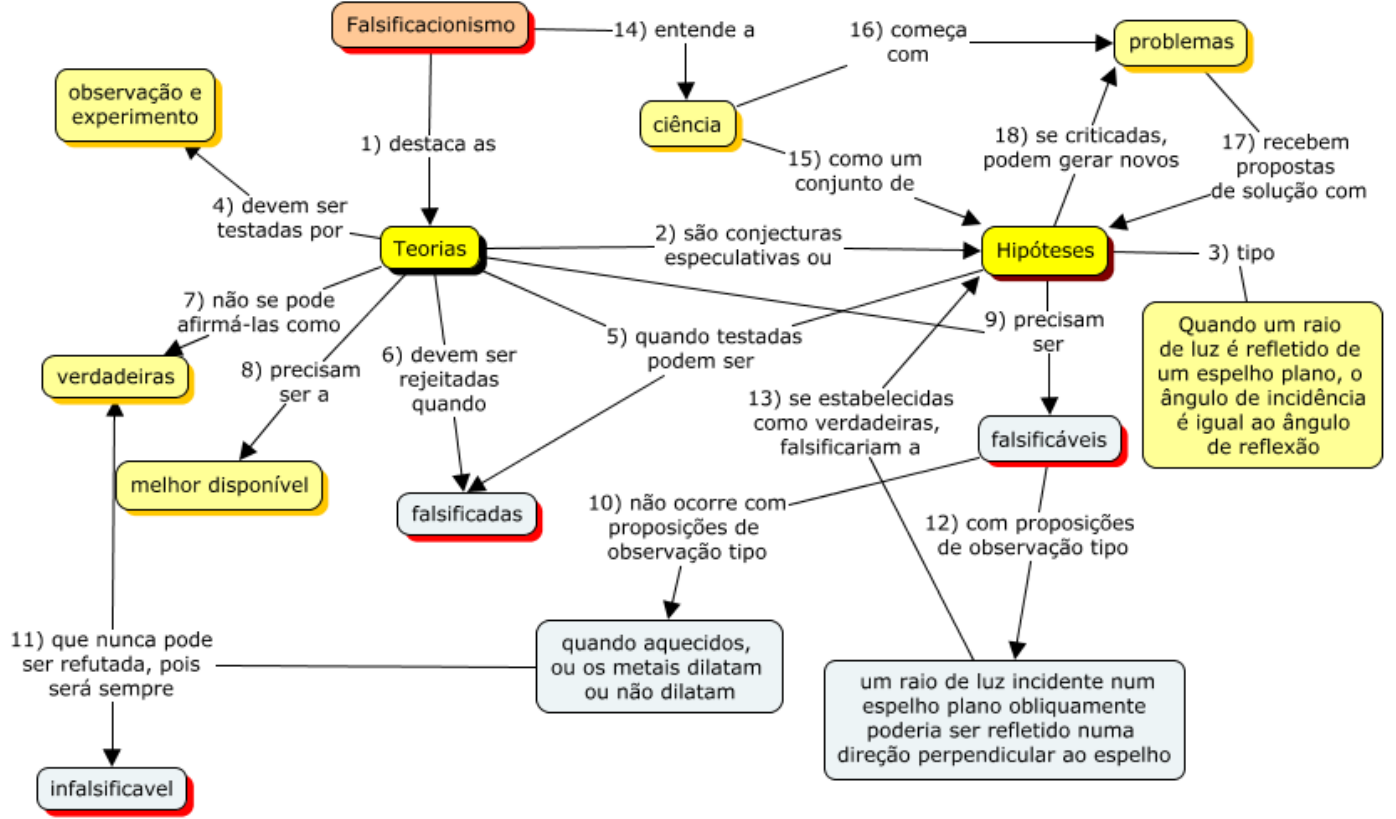

Figura 7 - O Falsificacionismo. Fonte: Elaborado pelo autor.

Ao Falar: "como explicar o movimento giratório dos planetas no céu, (Marte, por exemplo)?" (COSMOS, 2005, cap. 3), Sagan parece querer mostrar que a ciência começa com problemas e, assim, possibilita uma reflexão sobre a visão falsificacionista da ciência apresentada na figura 7. É possível perceber que no âmbito falsificacionista, os problemas podem ser solucionados com conjecturas especulativas, isto é, hipóteses que quando criticadas, podem gerar novos problemas (CHALMERS, 1993). Sagam apresenta os modelos de Ptolomeu e Copérnico nos fazendo pensar na seguinte questão: qual teoria seria a melhor disponível para a época?

Em um dos trechos da série, fala-se da "confrontação entre as duas visões do cosmos (ptolomaica e copernicana), centrada na Terra e centrada no Sol" (COSMOS, 2005, cap. 3), 
nos fazendo perceber, hoje, que mesmo que a visão copernicana fosse a melhor disponível, como se mostrara posteriormente, percebe-se agora que não poder-se-ia encará-la como verdade na ciência, pois os movimentos circulares propostos por Copérnico foram posteriormente aprimorados por Kepler como trajetórias elípticas.

Essa perspectiva de crescimento do conhecimento científico, entremostrando a importância de se trabalhar com teorias melhores do que as anteriores, está na essência da visão falsificacionista e pode ser compreendida observando-se a figura 8.

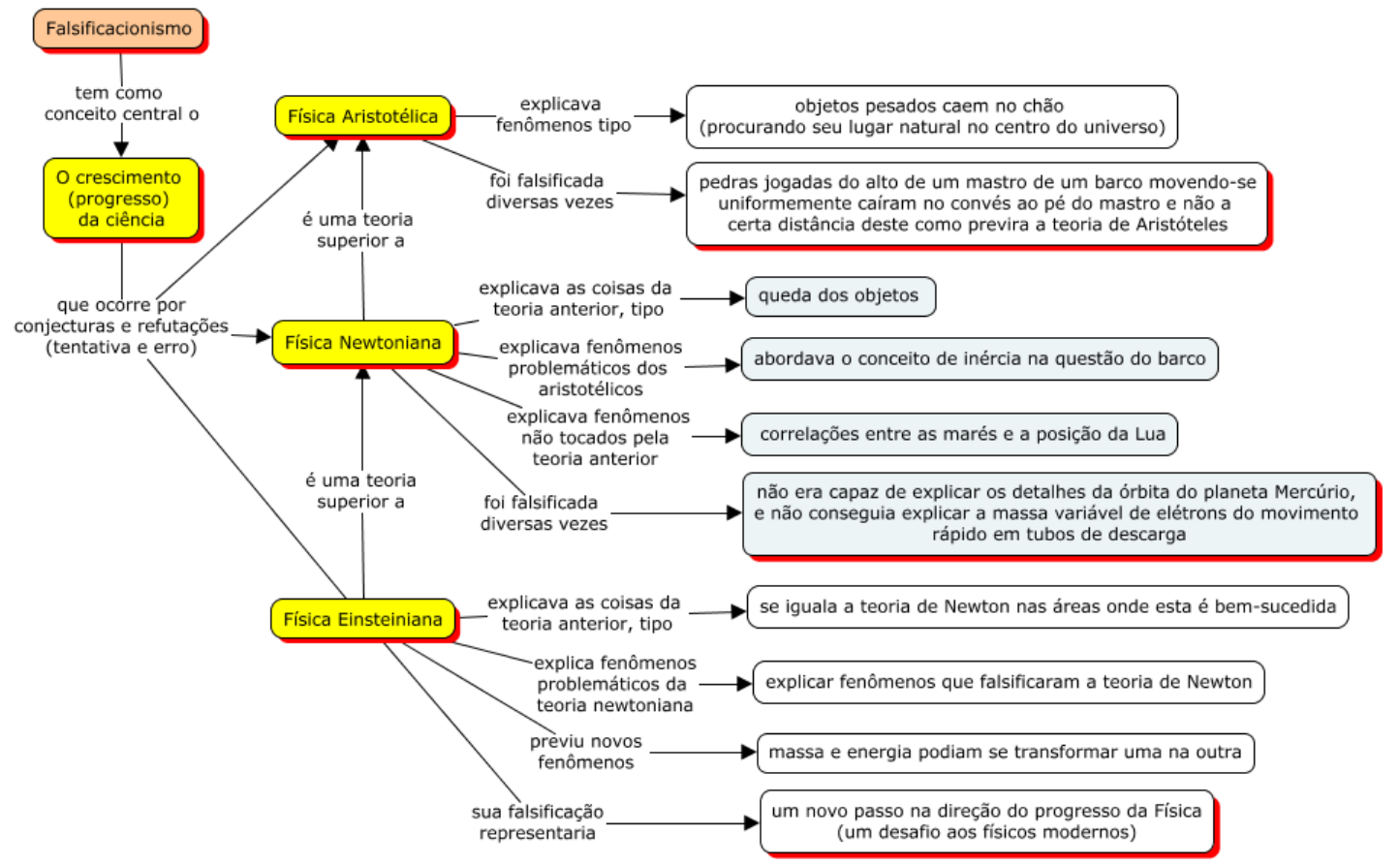

Figura 8 - O crescimento da ciência na visão falsificacionista. Fonte: Elaborado pelo autor

Pode-se observar que mesmo que uma teoria seja mais explicativa que a precedente e, por isso, considerada superior a antecedente, sua falsificação pode ser encarada como uma possibilidade de progresso na ciência, isto é, como um desafio à comunidade científica. Contudo, a ideia de que progresso da ciência está livre de interferências pode passar a falsa concepção de que "uma teoria bem estabelecida serve, em princípio, aos interesses de todas as perspectivas de valores mais ou menos de igual modo" (SANTOS, 2004, p. 79).

Essa concepção de neutralidade da ciência é solapada por Sagan quando menciona que "apoiado pela igreja, na idade das trevas, o modelo de Ptolomeu evitou efetivamente o avanço da Astronomia por 1500 anos" e quando fala que o modelo copernicano "irritou muita gente; a igreja católica, mais tarde, pois o trabalho de Copérnico em sua lista de livros proibidos", bem como quando apresenta as palavras de Martinho Lutero usadas para descrever Copérnico, quais sejam: "[...] as pessoas dão ouvido a um astrólogo presunçoso, esse tolo quer reverter toda a ciência da astronomia" (COSMOS, 2005, cap. 3). Pode-se perceber o quanto tais falas possibilitam "subordinar o empreendimento da ciência a interesses que representam valores sociais, morais, políticos ou religiosos" (LACEY, 2005, p. 42).

Observa-se, também, diante da divulgação científica apresentada por Carl Sagan, que há momentos na História da Ciência em que se revelam atividades de determinados personagens, como Ptolomeu e Kepler, cuja convivência entre ciência e pseudociência 
parece natural e até intensa. Isso fica evidente quando Sagan menciona que "durante uma aula de astrologia, Kepler inscreveu dentro do círculo dos zodíacos um triângulo com três lados iguais" (COSMOS, 2005, cap. 3). Percebe-se, com isso, que "não é porque o conhecimento é feito dentro da universidade ou por respeitados profissionais que não se caracterize como pseudociência" (PILATI, 2018, p. 122). Por isso, faz-se necessário apresentar uma representação imagética do "conhecimento" pseudocientífico descrita pela figura 9.

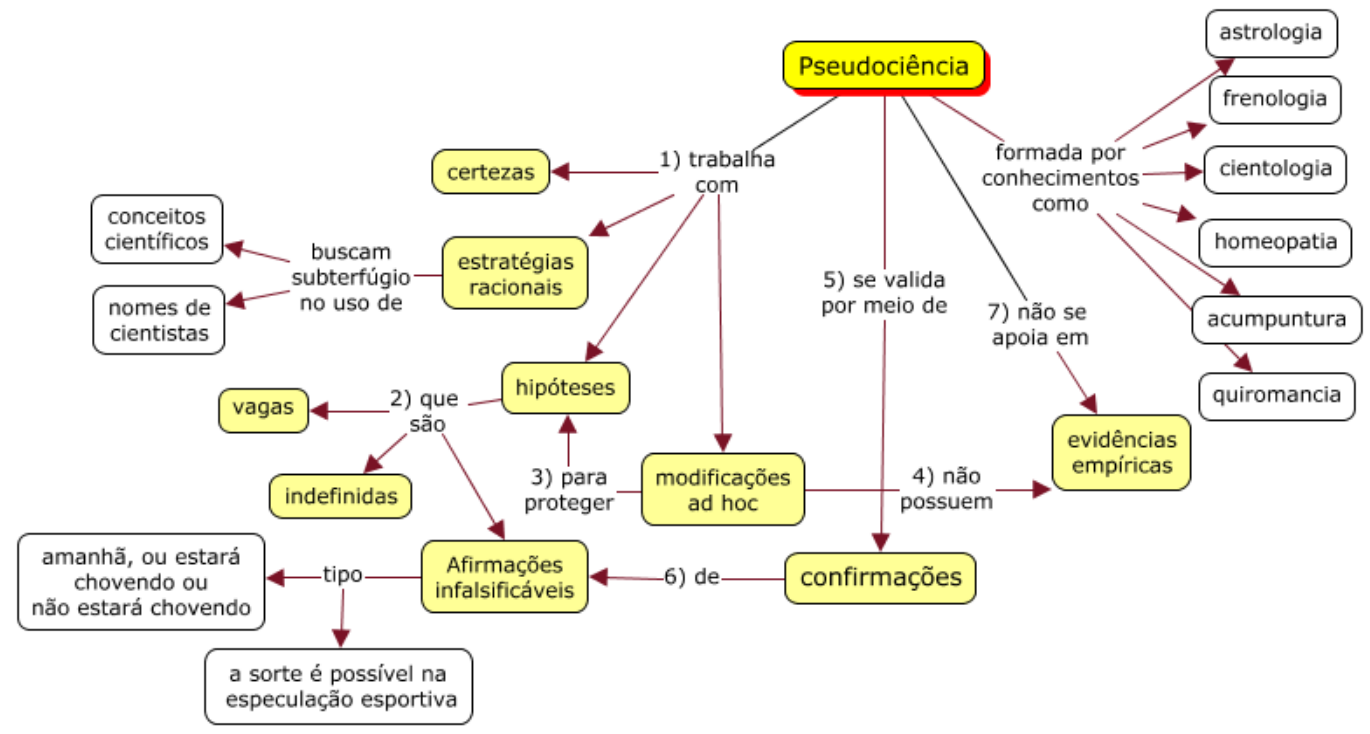

Figura 9 - O "conhecimento" pseudocientífico. Fonte: Elaborado pelo autor

Observando-se as características que descrevem a pseudociência, é possível perceber que apesar do discurso pseudocientífico apresentar argumentos racionais para a explicação da realidade, esconde-se o elemento central, qual seja a possibilidade de falsear o discurso diante do contato com evidências empíricas (PILATI, 2018). Assim, contemplando-se a figura 9, é possível perceber o quanto uma pseudociência como a astrologia, por exemplo, pode utilizar de estratégias racionais, servindo-se de conhecimentos físicos como gravidade e ondas eletromagnéticas, para buscar, por meio do "comprovado cientificamente", validar suas crenças (LEE, 2003).

Tal percepção pode ser compreendida, analisando-se a fala de Sagan quando diz que "foi à influência de Marte e Vênus que fez de seu pai um homem brutal? Um mercenário que o abandonou? Será que uma conjunção infeliz de planetas e um signo adverso fez de sua mãe uma mulher perversa e briguenta?" (COSMOS, 2005, cap. 3).

Fica claro que "o uso de argumentos de equiparação dessas crenças ao conhecimento científico é uma das formas que seus criadores e propagadores utilizam para persuadir as pessoas" (PILATI, 2018, p. 123-4). Contudo, a astrologia incorre no problema de não conseguir amparo de evidências empíricas que validem tais crenças, mesmo que vários astrólogos defendam que "a astrologia é testável, e que há indícios de que exista relação causal entre os corpos celestes e os eventos humanos" (LEE, 2003, p. 95). Sobre isso, é preciso "lembrar que inúmeras vezes a pseudociência é utilizada com má fé, destinada a usurpar o dinheiro da população em geral que ingenuamente acredita em evidências casuais, rumores e anedotas" (KNOBEL, 2008, p. 6).

É preciso estar atento à força das afirmações infalsificáveis, utilizadas comumente na pseudociência, enquanto reforço positivo na perspectiva de Skinner, pois como nunca são 
falsificadas, tais afirmações - ou melhor, as confirmações constantes delas - possibilitam aumentar o comportamento das pessoas de procurarem "ajuda" na astrologia, quiromancia, entre outras. Assim, as confirmações das afirmações infalsificáveis representam uma possibilidade de vulnerabilizar as pessoas ao charlatanismo, pois representam eventos que ocorrem posteriormente ao comportamento - "consultar" com pseudocientista - e que, subsequentemente, ampliam a frequência desse comportamento (LEFRANCOIS, 2008; MELO et al., 2020; MOREIRA, 1999).

Diante do exposto, faz-se necessário diferenciar a ciência da pseudociência e uma das formas de se fazer isso é elucidando as características do conhecimento científico, possibilitando discutir seus procedimentos, atitudes, sua natureza e a forma como se desenvolve. Isso possibilitará perceber, inclusive, que cada área de ciência pode apresentar um complemento pseudocientífico, pois os químicos ainda apresentam a alquimia, enquanto os físicos possuem a máquina de movimento perpétuo, os geofísicos precisam lidar com Terras chatas ou ocas, os psicólogos possuem boa parte da psicanálise e os astrônomos têm a astrologia (SAGAN, 1996). Por isso, a comparação entre as figuras 7 e 9 pode nos proporcionar um interessante caminho para tal diferenciação.

Percebe-se que enquanto a pseudociência trabalha com certezas, a ciência utiliza verdades provisórias; enquanto a pseudociência trabalha com afirmações infalsificáveis, a ciência utiliza hipóteses que quando falsificadas, podem ser rejeitadas; enquanto a pseudociência não trabalha com evidências testáveis, a ciência possibilita que suas teorias sejam testadas com observações e experimentos, oportunizando, com isso, o progresso do conhecimento científico.

Portanto, fica evidente que enquanto a pseudociência trabalha com afirmações vagas e indefinidas, que não correm risco e que nada nos diz sobre o mundo, a ciência é amparada por hipóteses informativas, isto é, aquelas que se expõem ao risco da falsificação (CHALMERS, 1993). Assim, pode-se dizer que o erro faz parte da ciência, mas quase sempre é dissimulado na pseudociência.

Por outro lado, vale destacar que ciência e pseudociência se diferenciam pela possibilidade de falsificar afirmações, mas na perspectiva falsificacionista, isto é, mediante a uma visão popperiana da ciência. Assim, por não ser falsificável, a astrologia não poderia ser compreendida como ciência. Porém, são várias as epistemologias que podem fundamentar essa discussão. Na compreensão indutivista, por exemplo, é por não ser derivada de dados de observação que a astrologia não é considerada ciência; por não se adequar a metodologia de um determinado programa de pesquisa, a astrologia não seria ciência na perspectiva de Imre Lakatos (1922-1974) (CHALMERS, 1993). Diante disto, pode-se perguntar: existem outras concepções, além dessas perspectivas racionalistas, para diferenciar ciência e pseudociência?

Uma visão relativista que poderia ser destacada aqui seria a das revoluções científicas de Thomas S. Kuhn (1922-1996), pois a existência de um paradigma é que proporcionaria tal distinção (CHALMERS, 1993), visto que a astrologia não possui um paradigma que a qualifique como ciência normal como ocorre com a mecânica newtoniana, por exemplo.

Nesse contexto, fica claro que a democratização da ciência, ampliando seu acesso às dimensões epistemológicas, procedimentais e atitudinais, pode representar um passo fundamental no combate ao obscurantismo e possibilitar uma sociedade preparada para tomar decisões nas áreas envolvendo ciência e tecnologia, fomentando um indivíduo atento a todo tipo de charlatanismo que insinue validar engodos como se fossem conhecimento 
científico. Por isso, o ensino que apresenta somente as descobertas da ciência e, no máximo, os seus produtos, sem se preocupar com seu método crítico, dificultará a distinção entre ciência e pseudociência (SAGAN, 1996).

\section{Considerações finais}

É importante resgatar e refletir a questão que norteia esse estudo, qual seja: quais contribuições ao processo de ACT podem surgir na Educação Científica quando se busca compreender a distinção entre ciência e pseudociência pela análise da série Cosmos de Carl Sagan?

Talvez, a primeira resposta a essa questão seja, de certa forma, frustrante, pois a demarcação entre ciência e pseudociência parece não ser tão simples como insinua o racionalismo falsificacionista quando apresenta como critério universal que afirmações científicas precisam ser falsificáveis e, além disso, resistirem a testes. Ora, mas qual critério universal devemos usar? Não poderia ser o indutivista cujo conhecimento científico se origina pela observação de fenômenos e experimentos? Aliás, um relativista kuhniano poderia até questionar: por que temos que usar um critério universal e, inclusive, atemporal como forma de avaliação para o conhecimento científico? Não seria melhor utilizar um paradigma que propusesse regras de governabilidade para esse conhecimento científico?

Diante do exposto, Carl Sagan parece nos proporcionar um interessante exercício de reflexão, pois um obstáculo para a compreensão sobre a demarcação entre ciência e pseudociência é exatamente o fato de termos diversas visões de ciências e, inclusive, vários tipos de pseudociências. Por outro lado, essa diversidade pode ser encarada com entusiasmo, pois nada impede que um professor, ou uma professora, possa utilizar uma dessas concepções, como a popperiana por exemplo, para inserir discussões epistemológicas nas aulas de ciências e, com isso, estimular tais questões na Educação Científica que, infelizmente, pouco discute a dimensão epistemológica da ciência.

A simples possibilidade de se compreender que a ciência elimina seus erros para prosperar e que suas hipóteses surgem oferecendo a possibilidade de serem refutadas, representa um elemento fundamental para diferenciá-la da pseudociência, pois a hipótese pseudocientífica, por outro lado, é gerada buscando alcançar invulnerabilidade a qualquer observação que possa refutá-la.

Discussões como essas, precisam fazer parte do ensino de ciências e, nesse aspecto, a série Cosmos de Carl Sagan entremostra-se como um interessante objeto de aprendizagem a ser apresentado nas aulas de ciências, pois oferece possibilidade de se promover a ACT por meio da articulação com seus eixos estruturantes, de se trabalhar conteúdos conceituais dos currículos, mas também de oportunizar as dimensões epistemológica e atitudinal da ciência como forma de estimular o interesse pelo conhecimento científico e de ampliar a compreensão sobre as suas características.

Numa perspectiva freiriana, pode-se dizer que a inserção da dimensão epistemológica da ciência, no ensino de ciências, representa um direcionamento à valorização da conscientização, sobretudo das camadas populares, pois possibilita contribuir para a superação da cultura do silêncio quando fomenta um indivíduo mais preparado para tomar decisões relacionadas a aspectos socioeconômicos ligados a relação C\&T. Por isso, a série Cosmos de Carl Sagan apresenta-se como uma interessante contribuição ao processo de alfabetização científica cívica e cultural da sociedade. 


\section{Referências}

AIKENHEAD, G. What is STS teaching? In: SOLOMON, J.; AIKENHEAD, G. STS education: international perspectives on reform. New York: Teachers College Press, p. 47-59, 1994.

AZEVEDO, M. C. P. S. de. Ensino por investigação: problematizando as atividades em sala de aula. In: CARVALHO, A. M. P. (Org.). Ensino de Ciências: unindo a pesquisa e a prática. São Paulo: Cengage Learning, p. 19-33, 2009.

BARDIN, L. Análise de Conteúdo. 3a reimpressão. São Paulo: Edições 70, 2011.

BRAGA, M.; GUERRA, A.; REIS, J. C. Breve História da Ciência Moderna, volume 2: das máquinas do mundo ao universo-máquina. Rio de Janeiro. Jorge Zahar Ed. 2004.

BRASIL. Ministério da Educação, Secretaria de Educação Fundamental. Parâmetros Curriculares Nacionais: Ciências Naturais. Brasília: Ministério da Educação, 1997.

BRASIL. Ministério da Educação, Secretaria de Educação Média e Tecnológica. Parâmetros Curriculares Nacionais (PCN) (Ensino Médio). Brasília: MEC, 2000.

BRASIL. Ministério da Educação. Secretaria da Educação Média e Tecnológica. Parâmetros Curriculares Nacionais + $(\mathrm{PCN}+)$ - Ciências da Natureza e suas Tecnologias. Brasília: MEC, 2002.

BRASIL. Ministério da Educação (MEC), Secretaria de Educação Básica (SEB), Ciências da natureza, matemática e suas tecnologias. Orientações Curriculares do Ensino Médio. Brasília: MEC/SEB, 2006.

CACHAPUZ, A. et al. (Org.). A necessária renovação do ensino de ciências. 3. ed. São Paulo: Cortez, 2011.

CANIATO, R. O céu. Campinas: Ed. Átomo, 2011.

CHASSOT, A. Alfabetização científica: questões e desafios para a educação. 5 ed. ljuí: Ed. Unijuí, 2011.

CHALMERS, A. F. O que é ciência afinal? 1. ed. São Paulo: Brasiliense. 1993.

COSMOS de Carl Sagan. Ed. Comemorativa de 25 anos. Vol. 1. Coleção Superinteressante vídeo. Direção: Adrian Malone. Produção: Gregory Andorfer \& Rob McCain. Intérprete: Carl Sagan. [S.1]: Abril, 2005. 1DVD (178 min), son., color

CUNHA, M. B.; CHANG, V. R. J. Fake Science: uma análise de vídeos divulgados sobre a pandemia. Amazônia: Revista de Educação em Ciências e Matemáticas, v. 17, n. 38, p. 139152, 2021.

FREIRE, P. Conscientização: teoria e prática da libertação: uma introdução ao pensamento de Paulo Freire. 3 ed., São Paulo: Moraes, 1980.

GIL-PÉREZ, D.; CARVALHO, A. M. P. de. Formação de professores de ciências. 9. ed. São Paulo: Cortez, 2009.

GOLDSCHMIDT, A. I.; SILVA, N. V.; MURÇA, J. S. E.; FREITAS, B. S. P. O que é Ciência?

Concepções de licenciandos em ciências biológicas e química. Contexto \& Educação, v. 31, n. 99, p. 173-200. 2016.

KNOBEL, M. Ciência e Pseudociência. Física na Escola, n. 1, v. 9, p. 6-9, 2008. 
LACEY, H. Como devem os valores influenciar a ciência? Filosofia Unisinos, n. 6, v. 1, p. 41-54, 2005.

LAGO, S. R. A inquisição não acabou. Curitiba: Nossa Cultura, 2017.

LEE, P. Ciências versus pseudociências. Curitiba: Expoente, 2003.

LEFRANCOIS, G. R. Teorias da Aprendizagem: o que a velha senhora disse. São Paulo:

Cengage Learning, 2008.

MARINELI, F. O terraplanismo e o apelo à experiência pessoal como critério epistemológico.

Caderno Brasileiro de Ensino de Física, v. 37, n. 3, p. 1173-1192, 2020.

MARTINAZZO, C. J.; MARTINS, T. M.; SILVA, S. P. A religação dos saberes a partir da Série Cosmos, de Carl Sagan. Contexto \& Educação, ano 33, n 104, p. 151-171, 2018.

MELO, M. G. de A. Jogo Tríptico na formação inicial do professor de ciências: uma proposta de ensino de Física sob o enfoque CTS que busca promover ACT. Tese (Doutorado em Ensino de Ciências e Tecnologia) - Universidade Tecnológica Federal do Paraná. Ponta Grossa, 2019.

MELO, M. G. de A. A música controversa como instrumento de alfabetização científicotecnológica: um arquétipo de objeto de aprendizagem no ensino de ciências. Experiências em Ensino de Ciências, v. 15, n. 3, p. 124-145. 2020.

MELO, M. G. de A.; NEVES, M. C. D.; SILVA, S. de C. R.; PINHEIRO, N. A. M.; MIQUELIN, A. F. O livro didático de Física e suas tendências: uma análise necessária da influência Behaviorista no Ensino de Ciências. REnCiMa, v. 11, n. 5, p. 185-203. 2020.

MOREIRA, M. A. Teorias de Aprendizagem. São Paulo: EPU, 1999.

NEVES, M. C. D. Astronomia de Régua e compasso: de Kepler a Ptolomeu. Campinas: Papirus, 1986.

NEVES, M. C. D.; SILVA; J. A. P.; FUSINATO, P. A.; PEREIRA, R. F. Da Terra, da Lua e além. 2 ed. Maringá: Massoni, 2010.

NEVES, M.C.D.; SILVA, J.A.P. da. Da lua pós-copernicana: a relação ciência-arte de Galileo e Cigoli no Renascimento. Maringá, Eduem, 2010.

PILATI, R. Ciência e pseudociência: Porque acreditamos naquilo que queremos acreditar. São Paulo: Contexto, 2018.

SAGAN, C. O mundo assombrado pelos demônios: a ciência vista como uma vela no escuro. São Paulo: Companhia das Letras, 1996.

SANTOS, R. S. A questão da neutralidade: um debate necessário no ensino de ciências.

Dissertação apresentada à Faculdade de Educação da Universidade de São Paulo, São Paulo, 2004.

SASSERON, L. H.; CARVALHO, A. M. P. de. Alfabetização científica: uma revisão bibliográfica. Investigações em ensino de ciências, v. 16, n. 1,59-77, 2011.

SHEN, B. S. P. Science literacy. In: American Scientist, New York, v. 63, 1975. 